\title{
PBDEs (polybrominated diphenyl ethers) pose a risk to captive giant pandas
}

\section{Citation}

Chen, Yi-ping, Ying-juan Zheng, Qiang Liu, Aaron M. Ellison, Yan Zhao, and Qing-yi Ma. 2017. "PBDEs (polybrominated Diphenyl Ethers) Pose a Risk to Captive Giant Pandas." Environmental Pollution 226 (July): 174-181. doi:10.1016/j.envpol.2017.04.023.

\section{Published Version}

10.1016/j.envpol.2017.04.023

\section{Permanent link}

http://nrs.harvard.edu/urn-3:HUL.InstRepos:32686919

\section{Terms of Use}

This article was downloaded from Harvard University's DASH repository, and is made available under the terms and conditions applicable to Other Posted Material, as set forth at http:// nrs.harvard.edu/urn-3:HUL.InstRepos:dash.current.terms-of-use\#LAA

\section{Share Your Story}

The Harvard community has made this article openly available.

Please share how this access benefits you. Submit a story.

\section{Accessibility}


1 PBDEs (polybrominated diphenyl ethers) pose a risk to captive giant pandas

2 Yi-ping Chen ${ }^{\text {a, b*, }}$, Ying-juan Zheng ${ }^{\text {a }}$, Qiang Liu ${ }^{\text {a }}$, Aaron M. Ellison ${ }^{\mathrm{c}}$, Yan Zhao ${ }^{\mathrm{a}}$, Qing-yi Mad

3 a State Key Laboratory of Loess and Quaternary Geology, Institute of Earth Environment, CAS, Xi’an, 710075,

4 China

$5 \quad$ b College of Life Science, Northwest Normal University, Lanzhou 730070, China

$6 \quad{ }^{\mathrm{c}}$ Harvard University, Harvard Forest, Petersham, Massachusetts, 01368, USA

$7 \quad$ d Shaanxi Wild Animal Research Center, Zhouzhi, Xi’an, 710402, China

8

9 *Corresponding author: Dr YP Chen, Institute of Earth Environment, Chinese Academy of Science, No. 97,

10 Yan-Xiang Road, Xi’an, 710061, China; Tel: +86-29-62336269; Fax: +86-29 -62336269; E-mail:

11 chenyp@ieecas.cn

12 Abstract

The Qinling subspecies of giant panda (Ailuropoda melanoleuca qinlingensis) is highly endangered; fewer than 350 individuals still inhabit the Qinling Mountains. Previous research revealed that captive pandas were exposed to bromine, so we hypothesized that captive pandas

16 also were exposed to, and affected by, polybrominated diphenyl ethers (PBDEs). To test this

17 hypothesis, we sampled blood and feces of captive and wild pandas, their drinking water, food

18 (bamboo leaves) from the Shaanxi Wild Animal Research Center (SWARC) and the Foping

19 National Nature Reserve (FNNR), and supplemental feedstuff fed to captive pandas at SWARC.

20 We found 13 congeners of PBDEs in fecal samples, of which BDE47, BDE66, BDE71, BDE99,

21 and BDE154 predominated; total PBDE concentration in feces of captive pandas was 255\% 
22 higher than in wild pandas. We found nine PBDEs congeners in blood samples: BDE153 and BDE183 predominated, and concentrations of PBDEs in blood from captive pandas also were

24 significantly higher than in wild pandas. The primary source of PBDEs appears to be the bamboo fed to the pandas: total concentration of PBDEs were 5473 and $4835 \mathrm{pg} \cdot \mathrm{g}^{-1}$ in the bamboo

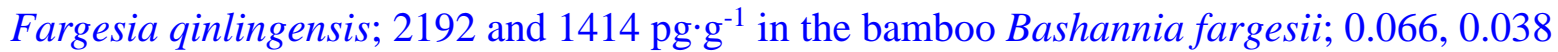
$\mathrm{pg} \cdot \mathrm{mL}^{-1}$ in drinking water; and $28.8 \mathrm{pg} \cdot \mathrm{g}^{-1}$ in supplemental feedstuff for captive and wild pandas, respectively. BDE99 and BDE47 could threaten the health of captive pandas, whereas other PBDE congeners may pose additional health risks to the captive pandas. In the short term, this risk may be ameliorated by strict control of food quality. In the long term, however, reducing air, water and soil contamination to improve environmental quality will best reduce these risks.

Keywords: PBDEs; Captive Panda; Feces and Blood; Food; Health risk

Capsule: Captive pandas were exposed to higher concentrations of toxic PBDEs than wild pandas. PBDEs are most prevalent in the bamboo fed to the pandas, highlighting the need for quality control on the food supply of captive pandas.

\section{Introduction}

The giant panda (Ailuropoda melanoleuca) is one of the rarest animals in the world. Approximately 1800 individuals remain in anthropogenically fragmented habitats (SFA, 2015), of which $<350$ individuals are of the Qinling subspecies (A. melanoleuca qinlingensis) living in the 
43 Qinling Mountains of China (SFA, 2015). In the last several decades, two strategies have been used to protect this species. One strategy is ex-situ breeding in, for example, the Beijing Zoo, the Wolong Breeding Center, and the Shaanxi Wild Animal Research Center (SWARC). The other strategy is the establishment of natural conservation zones to preserve panda habitat. In the last several decades, 67 conservation zones, with a total area $>43,600 \mathrm{~km}^{2}$, have been established (SFA, 2015).

It is generally assumed that captive breeding centers can effectively protect giant pandas from the adverse impacts of human activities. However, canine distemper virus has killed at least four pandas at SWARC (Mara, 2015) suggesting that new measures are needed to protect captive individuals of this iconic endangered species. Environmental pollution further stresses captive animals. For example, we have shown that captive pandas are exposed to heavy metals including cadmium, zinc, chromium, arsenic and lead (Chen et al., 2016). We also found that chlorine and bromine were $690 \%$ and $330 \%$ higher in feces of captive pandas than in those of wild pandas (Chen and Ma, 2017), and we therefore hypothesized that captive pandas may be exposed to and affected by polybrominated diphenyl ethers (PBDEs).

PBDEs are brominated flame retardants that are used in electronic equipment, textiles, cabinets for television and computers, and in many plastic products (WHO, 1994; Darnerud et al., 2001; Kim et al., 2012). PBDEs are lipophilic, are released slowly into the environment, can bioaccumulate in tissues of humans and other mammals, and are toxic to them (Hooper and McDonald, 2000; De Wit, 2002; Hu et al., 2008). Exposure of laboratory animals to high concentrations of PBDEs can suppress production of antibodies and proliferation of lymphocytes 
64 (Darnerud and Thuvander, 1998), decrease thymic weights (Fowles et al., 1994), cause

65

66

67

68

69

70

71

72

73

74

75

76 immunomodulatory turbulence, and lead to hormonal deficits (Eriksson et al., 2001; Branchi et

al., 2003). Modulating effects of PBDE exposure on endocrine systems of wild animal also have been documented (Legler and Brouwer, 2003; Darnerud, 2003). Recent research showed that giant pandas were exposed to PCDDs, PCDFs, PCBs, and heavy metals from the bamboo they eat (Fargesia qinlingensis and Bashania fargesii) in both captive breeding centers and in situ in conservation areas (Chen et al., 2016). However, there has been no research on exposure of captive or wild pandas to PBDEs, or their concentrations in panda feces and blood.

The objective of this study was to (1) test whether captive or wild pandas are exposed to PBDEs. (2) document and compare the concentrations of PBDEs in wild and captive pandas; and (3) identify possible sources of PBDEs contamination. Feces, drinking water, and food (bamboo) were collected from SWARC and the Foping National Nature Reserve (FNNR), and blood samples and supplemental feedstuff were sampled at SWARC (Fig.1). 


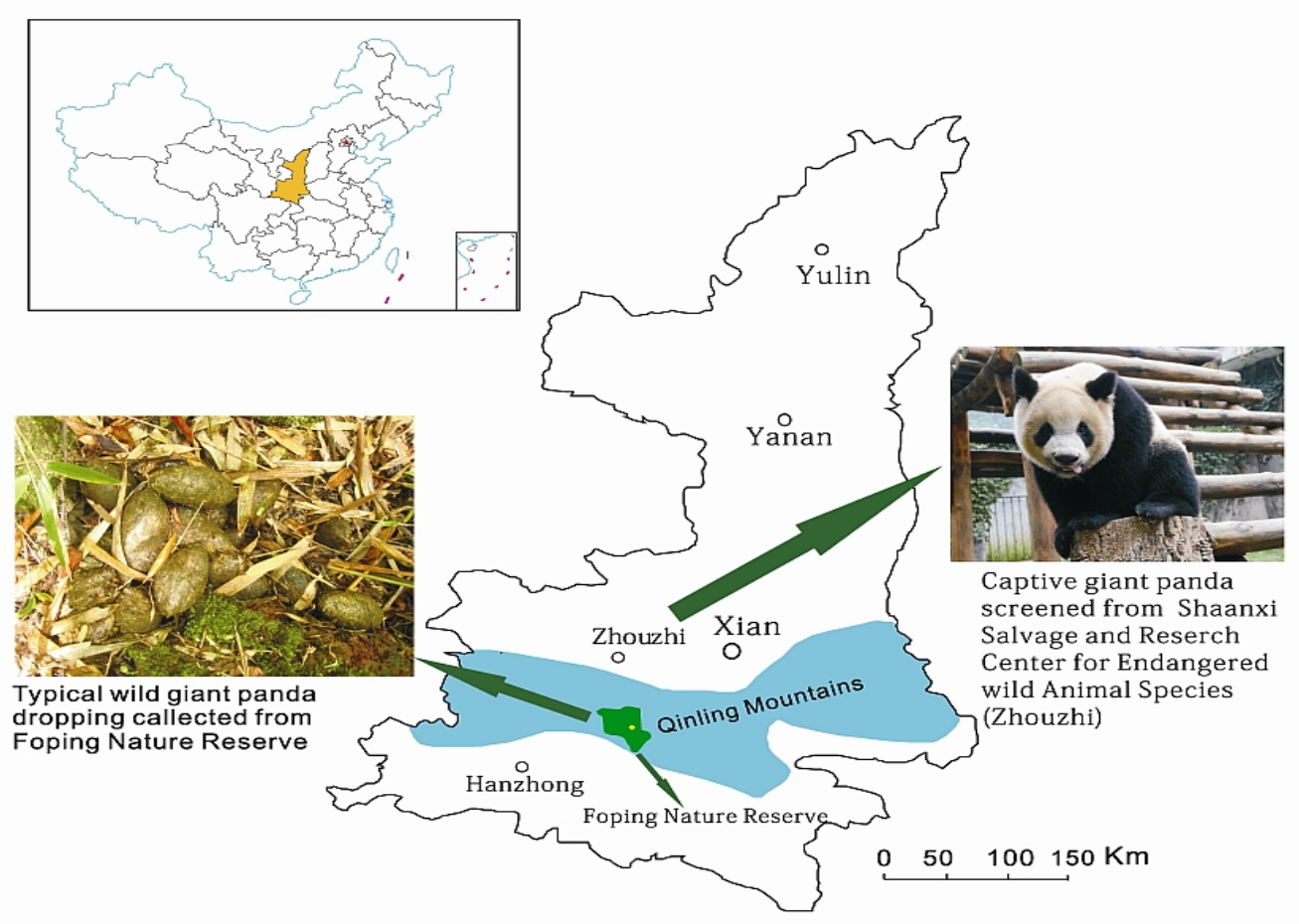

Figure 1. Sample Collection Sites. The Shannxi Wild Animal Research Center (SWARC) is located at $34^{\circ} 04^{\prime} \mathrm{N}, 108^{\circ} 19^{\prime} \mathrm{E}$ in Zhouzhi County, Shaanxi province. The Foping National Nature Reserve (green shaded area) is located in the area bounded by $33^{\circ} 33^{\prime}-3344^{\prime} \mathrm{N}$, $107^{\circ} 40^{\prime}-107^{\circ} 55^{\prime} \mathrm{E}$ within the Qinling Mountains (blue shaded area).

79 Materials and methods

80 Sample collection

81 Giant pandas are protected in China, capturing them is illegal, and so samples from wild

82 animals must be collected non-invasively. Fecal samples (droppings: Fig. 1) were collected from

8316 different locations within FNNR. Sampling locations were spaced 10-km apart and every four

84 independent samples were pooled into a mixed sample. Droppings of 16 captive pandas were 
collected from SWARC, which was established in 1987 to conserve the Qinling panda. Each set of 16 fecal samples were pooled for analysis into four samples each consisting of four independent samples.

Fresh leaves of living plants (500 g) of the two bamboo species (Fargesia qinlingensis, Bashania fargesii) that are the primary food of the panda were collected in proximity to where the droppings were collected at FNNR and around SWARC. Water samples (500 mL) were collected into Pyrex borosilicate amber glass bottles from streams at FNNR near where we collected the droppings, and from the SWARC water supply. At both FNNR and SWARC, 12 samples of each bamboo species and of freshwater were collected. They subsequently were pooled to produce four mixed samples each consisting of three independent samples from each site. In addition, four samples of mixed feedstuff, provided as a nutrient supplement for captive pandas, also were collected from SWARC.

Finally, blood samples were obtained from three similarly-aged pandas rescued from the Qinling Mountains and three captive pandas bred at SWARC. These blood samples were residuals from regular, routine physical examinations of the individual pandas. Prior to examination, the pandas were anesthetized with 25\% ketamine (dosage: $8 \mathrm{mg} \cdot \mathrm{kg}^{-1}$ ). After collection, the blood was placed in EDTA tubes and frozen at $-80^{\circ} \mathrm{C}$ for analysis of PBDEs.

\section{Sample preparation and extraction}

PBDE congeners were analyzed using US Environmental Protection Agency (EPA) method 1614 with minor modifications (Li et al., 2008). Bamboo, feces, and feedstuff samples 
were freeze dried and then homogenized by passing them through a stainless steel sieve (0.5-mm mesh). Each 3-g homogenized sample was spiked with a ${ }^{13} \mathrm{C}$-labeled surrogate standard (EPA methods 1613B and 1668A) and extracted using accelerated solvent extraction (ASE) for $24 \mathrm{~h}$ with dichloromethane $(150 \mathrm{~mL})$ and hexane $(150 \mathrm{~mL})$ at $55^{\circ} \mathrm{C}$. After ASE, acidic silica (15 g, $30 \% \mathrm{w} / \mathrm{w}$ ) was added to the sample to remove lipids. Then, $5 \mathrm{~g}$ of anhydrous sodium sulfate was added to the extract. The extract sample was rotary evaporated to $2 \mathrm{ml}$ and then passed through a multi-layered silica-gel column that had been pre-cleaned by hexane (100 mL). After the sample was loaded, the PBDE congeners were eluted with $70 \mathrm{ml}$ hexane followed by $70 \mathrm{~mL}$ dichloromethane. The eluant was then concentrated to $2 \mathrm{ml}$ on the rotary evaporator. Its volume was further reduced with a gentle nitrogen flow and the solvent was changed to $20 \mu \mathrm{L}$ nonane in a minivial.

PBDEs in water samples were extracted using US EPA method 1614. Prior to extraction, $1 \mathrm{~L}$ of the liquid samples were filtered using $0.45-\mu \mathrm{m}$ microporous membranes to remove the particle phase and then spiked with a ${ }^{13} \mathrm{C}$-labeled BDE-LCS standard. Organic halogen pollutants were adsorbed by siphon, $50 \mathrm{~mL}$ of acetone was used to flush the pillars and a 100 -mL mixture of acetone and water was collected. Resins were extracted using ASE for $24 \mathrm{~h}$ with dichloromethane $(300 \mathrm{~mL})$ and hexane $(300 \mathrm{~mL})$ at $55^{\circ} \mathrm{C}$. After ASE, a $15-\mathrm{mL}$ acetone-cleaned soxhlet extractor and zeolite was used to obtain a 430-mL solution, which was transferred to a 1000-mL separatory funnel, washed with $100 \mathrm{~mL}$ of ultrapure water for 3 times, and extracted with 30-mL n-hexane for 3 times to obtain a clear and transparent organic phase solution. This organic phase solution was evaporated to $2-3 \mathrm{~mL}$ and purified on the silica gel column. After 
127 adding $50 \mathrm{ml}$ n-hexane and evaporateding to $2-3 \mathrm{~mL}$, we added $15 \mathrm{~mL}$ isooctane, evaporated to

$128 \quad 2-3 \mathrm{~mL}$ and used 6-mL isooctane to clean. The solution was purged by nitrogen stream and

129 diluted to $1 \mathrm{~mL}$ in a brown bottle at $-20^{\circ} \mathrm{C}$ for further analysis.

130

131 Instrumental analysis

132

BDEs 17, 28, 47, 66, 71, 85, 99, 100, 138, 153, 154, 183, and 190 were analyzed using

133

gas chromatography (Agilent 6890, USA) coupled with a high-resolution mass spectrometer

134 (HRMS). The HRMS (Waters Micromass, Manchester, UK) operated in selected ion

135

monitoring (SIM) mode with resolution $>10,000$. The $\mathrm{m} / \mathrm{z}$ ratio of all the PBDE congeners was

136

79 and 81 except for BDE47 (m/z 325 and 327), BDE99 (m/z 404 and 406) and BDE183 (m/z

137

562 and 564). Exactly $1 \mu \mathrm{L}$ of the sample was injected with a CTC PAL autosampler in splitless

138 mode into an HB-5 $(30 \times 250-\mu$ m i.d. $\times 0.1-\mu m$ film thickness $)$ capillary column for separation.

139 The flow rate of the carrier gas was $1.2 \mathrm{~mL} / \mathrm{min}$ and the carrier gas was Helium. The program

140 was as follows: the injector was temperature programmed to ramp from $60{ }^{\circ} \mathrm{C}$ to $320{ }^{\circ} \mathrm{C}$ at

$141150{ }^{\circ} \mathrm{C} / \mathrm{min}$. The oven started at $80{ }^{\circ} \mathrm{C}$ held for $1 \mathrm{~min}$, increased to $200{ }^{\circ} \mathrm{C}$ at $10 / \mathrm{min}$, held at

$142200{ }^{\circ} \mathrm{C}$ for $1 \mathrm{~min}$, increased to $300{ }^{\circ} \mathrm{C}$ at $20^{\circ} \mathrm{C}$ min, and then held at $300{ }^{\circ} \mathrm{C}$ for $5 \mathrm{~min}$. The

143 temperature of the ion source was $150{ }^{\circ} \mathrm{C}$.

144

145 Quality assurance and quality control

146 All solvents were pesticide-residue grade and were purchased from Fisher (Hampton, NH,

147 USA). Silica gel was obtained from Merck (silica gel 60, Darmstadt, Germany). ${ }^{13} \mathrm{C}$ labeled 
surrogate and labeled injection standards were purchased from Wellington Laboratories (Guelph,

149

150

151

152

153

154

155

156

157

158

159

160

161

162

163

164

165

166

167

168

Canada).

All analytical procedures were checked by the strict quality assurance and control

measures to avoid sample- and cross-contamination. Reference material and 3 blank control

samples (ultrapure water) were analyzed using the same methods as described above. Triplicate

samples were analyzed to determine repeatability and reproducibility. To monitor analytic losses,

all samples were spiked with internal standards of ${ }^{13} \mathrm{C}$-labeled BDE47, 99, and 153. The mean

recoveries of ${ }^{13} \mathrm{C}$-labeled surrogate PBDE congeners 47, 99 and 153 were in the range of $54.2 \pm$

$12.1 \%, 66.0 \pm 10.1 \%, 102.2 \pm 20.1 \%$, respectively, which were well in the limits according to

US EPA Method 1614; all the content of PBDEs in the control (blank) samples were below the

limit of detection (LOD), which for BDEs 17, 28, 47, 66, 71, 85, 99, 100, 138, 153, 154, 183,

and 190 are $5,4,3,15,6,7,7,7,4,1,12$, and $4 \mathrm{pg} \cdot \mathrm{g}^{-1}$, respectively). If concentrations of actual

samples fell below LOD, 1/2 of the LOD values were used in subsequent statistical analysis.

\section{Data analysis}

Correlation analysis (CA) and principal components analysis (PCA) were used to analyze the association between 13 PBDE congers in different samples. Paired samples were analyzed using $t$-tests. All statistical analyses were done using the IBM statistical package SPSS 20.0 (IBM Corp., USA).

\section{Evaluation methods}



detailed in the Exposure Factors Handbook (US EPA 1997). Assuming that giant pandas only

171 feed on bamboo leaves, average daily dose (ADD) was calculated as:

$$
A D D=\frac{C \times I R_{S} \times E F \times E D}{B W \times A T}
$$

173 where $C$ is concentration of PBDEs $(\mathrm{mg} / \mathrm{kg}), I R_{S}$ is the ingestion rate of bamboo, $E F$ is the

174 exposure frequency (350 day/year), $E D$ is the exposure duration (10.36 years), $B W$ is the average

175 body weight (105 kg, from mid-range of 80-130 kg [Zhang and Wei 2006]), and AT is the 176 averaging time (3781.4 days). Noncancer toxic risk was determined by the model hypothesis of HQ (Hazard Quotient):

where $R f D_{o}$ is the reference dose of PBDEs (US EPA, 1997). Risk increases with HQ (Hang et al.

180 2009). If $H Q \leq 1$, risk exposure is relatively safe. If $1<H Q \leq 10$, considerable threat is

181 suggested, Finally, if $H Q \geq 10$, high chronic risk is suggested.

\section{Results}

\section{Concentrations of PBDEs}

Total PBDEs concentrations were consistently and significantly greater in captive pandas 186 and their food supply than in wild pandas and their food and water supply (Fig. 2). In the fecal 187 samples, $\Sigma 13$ PBDE of captive pandas was 2.55 times greater than in wild pandas (Fig. 2A). 
189 higher, in leaves eaten by captive pandas (Figs. 2B, 2C). Water samples had low concentrations 190 of PBDEs (Fig. 2D).

191 Thirteen congeners of PBDEs were found in fecal samples; BDE47, BDE66, BDE71, 192 BDE99 and BDE154 predominated in captive pandas (Fig. 3A). Of the dozen congeners found in 193 the two bamboo species eaten by captive pandas, BDE47 and BDE99 predominated in Fargesia 194 qinlingensis and Bashania fargesii, respectively (Figs. 3B, 3C). Although captive pandas were 195 exposed to somewhat higher concentrations of PBDEs in their water supply (Fig. 2D), the 196 concentrations of each congener were quite low and none predominated (Fig. 3D). Ten PBDE 197 congeners were found in the supplemental feedstuff provided for captive pandas, with BDE28 198 and BDE183 predominating (Fig. 3E). Finally, nine PBDE congeners were found in the blood 199 samples collected from SWARC. BDE153 and BDE183 were the predominant congeners in 200 captive panda blood samples, and occurred in significantly higher concentrations than in blood 201 sampled from wild pandas (Fig. 3F). 

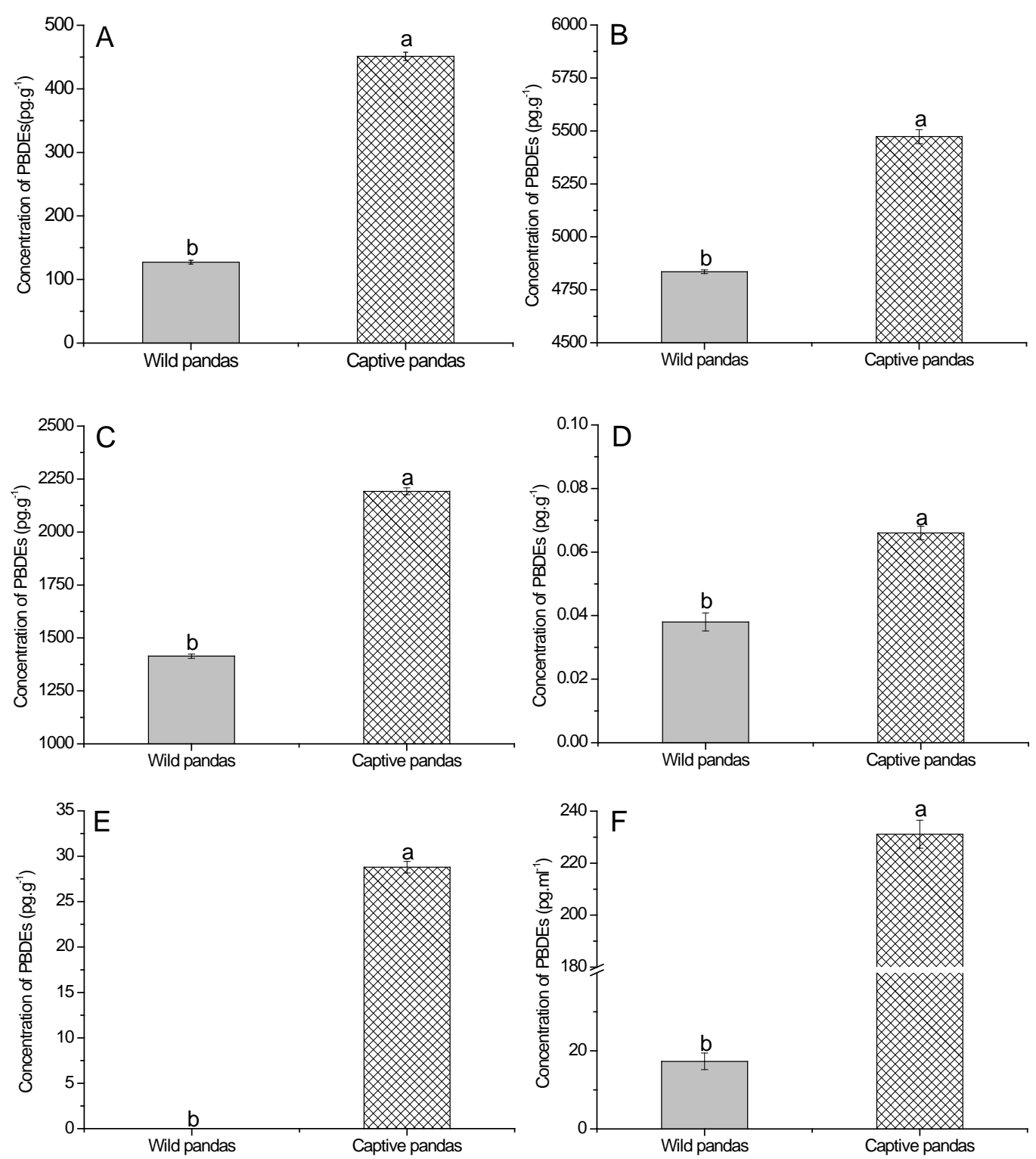

Fig. 2. Total concentrations of PBDEs ( $\sum 13 \mathrm{PBDEs}$ ) in (A) fecal samples; (B) leaves of Fargesia qinlingensis; (C) leaves of Bashania fargesii; (D) drinking water; (E) supplemental feedstuff; and (F) blood sample of wild (gray bars) and captive (cross-hatched bars) giant pandas. The concentrations of PBDEs in A, B, C and E are based on dry weight. In (F), the wild pandas were three 17-year old individuals rescued from Qingling and the captive pandas were 8-9-years old. Bars (means $\pm 1 \mathrm{SE}$ of the mean from $\mathrm{n}=4$ independent replicates comprising three or four pooled samples). Different letters indicate significant differences between the wild and captive pandas identified using Tukey HSD test (all $P<0.01$ ). $\mathrm{pg} \cdot \mathrm{g}^{-1} \mathrm{lw}^{-1}=$ nanograms per gram lipid weights. 

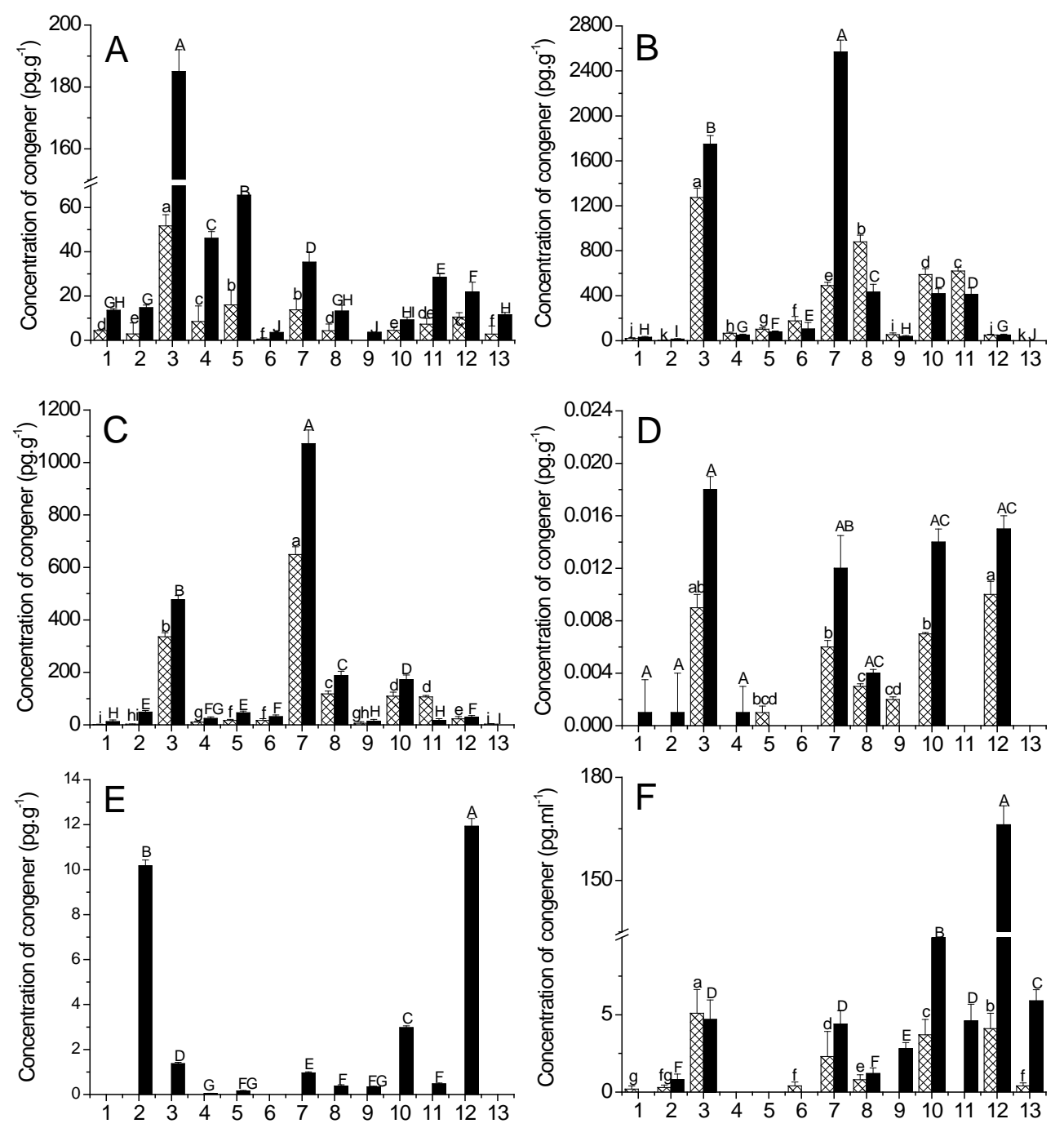

Fig. 3. Concentrations of individual PBDE congeners in (A) feces; (B) leaves of Fargesia qinlingensis; leaves of Bashania fargesii; (D) drinking water; (E) supplemental feedstuff; and (F) blood from wild (cross-hatched bars) and captive (black bars) giant pandas. Numbers $1-13$ on the $x$-axis denote different congeners, respectively: BDE17; BDE28; BDE47; BDE66; BDE71; BDE85; BDE99; BDE100; BDE138; BDE153; BDE154; BDE183; BDE190.

216 Different letters indicate significant differences between captive and wild pandas $(P<0.05)$.

\section{Statistical results}

The highest positive correlations in $\Sigma 13$ PBDEs were detected for feces and blood $v s$. 

congeners (Fig. 4). In leaves of Fargesia qinlingensis, the first three principal axes accounted for $87.8 \%$ of the variance (Fig. 4A), whereas they accounted for $62.5 \%$ for Bashania fargesii (Fig. 4B), and 77.4\% in feedstuff (Fig. 4C). Only one grouping was found for PBDEs in drinking water (19.8\% of the variance; Fig. 4D). The PCA identified clusters of the congeners BDE47, BDE66, BDE71, BDE99, and BDE154 in leaves of Bashania fargesii that matched the predominant congeners found in fecal samples (compare Fig. 4B with Fig. 3A).

230 Table 1 Spearman correlation matrix for PBDEs measured in captive samples

\begin{tabular}{llllll}
\hline & $\begin{array}{l}\text { Fargesia } \\
\text { qinglingensis }\end{array}$ & $\begin{array}{l}\text { Bashania } \\
\text { fargesii }\end{array}$ & Blood & Water & Feces \\
\hline Bashania fargesii & $0.89^{* *}$ & & & \\
Blood & $0.92^{* *}$ & $0.92^{* *}$ & & \\
Water & -0.11 & -0.10 & 0.15 & & \\
Feces & $0.90^{* *}$ & $0.88^{* *}$ & $0.93^{* *}$ & -0.09 & \\
Feedstuff & $0.73^{* *}$ & $0.75^{* *}$ & $0.88^{* *}$ & 0.309 & $0.79^{* *}$ \\
\hline
\end{tabular}



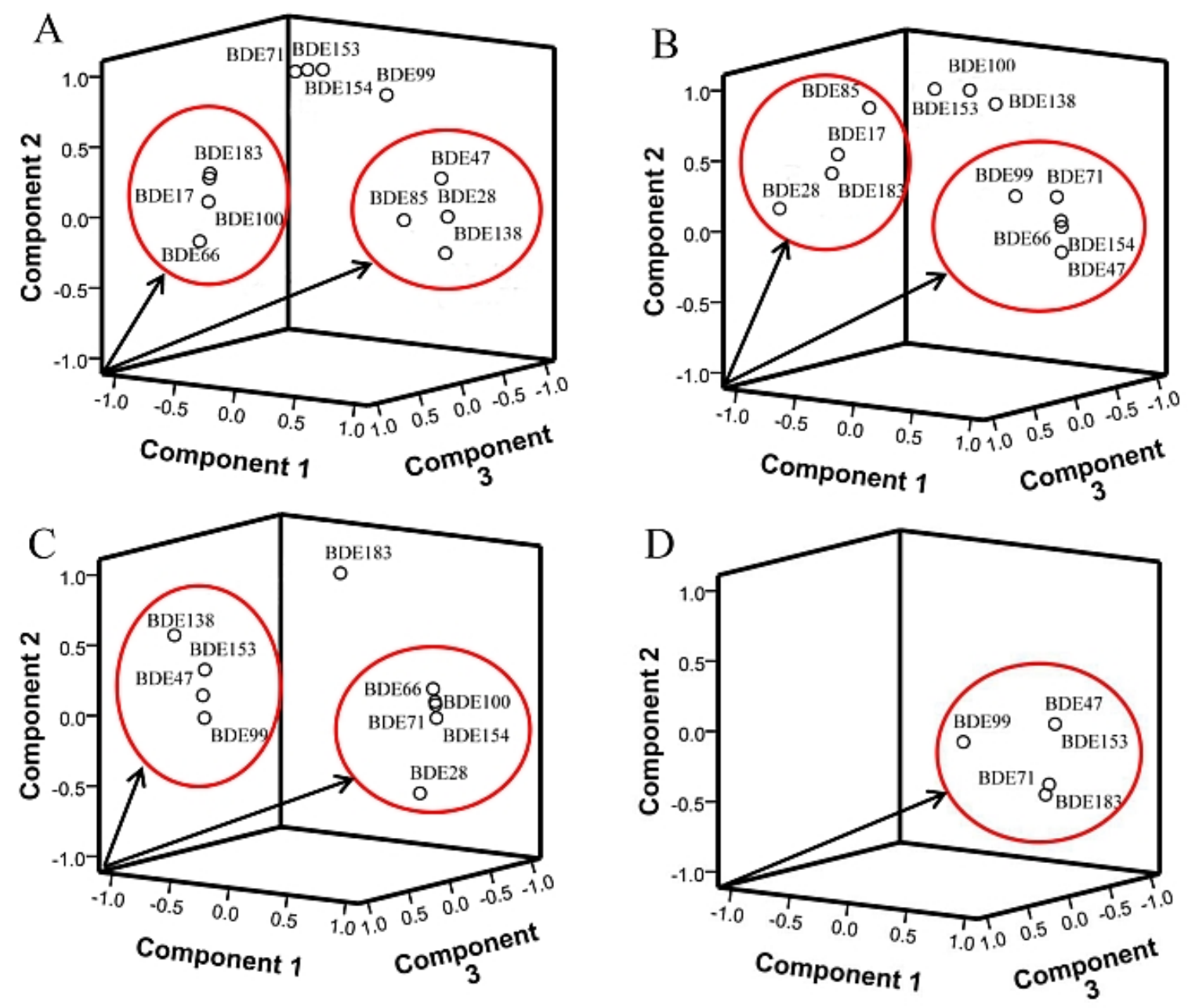

232

233

234

235

236

237

238

239

240

241

242

Fig. 4. Principal component triplot (principal axes 1-3) for 13 PBDE congeners in (A) leaves of Fargesia qinglingensis; (B) leaves of Bashania fargesii; (C) supplemental feedstuff; and (D) drinking water of samples taken at SWARC.

\section{Health risk assessment}

The ordering of hazard quotients $(H Q)$ of the top five PBDE congeners in captive pandas was BDE99 (1.60) > BDE47 (1.10) > BDE100 (1.07) > BDE153 (0.97) > BDE154 (0.55), and was BDE47 (1.20) > BDE100 (0.99) > BDE154 (0.75) > BDE153 (0.57) > BDE99 (0.55) in wild pandas. with $H Q$ values $>1$, BDE99 and BDE47 appear to pose a significant health risk to captive giant pandas, whereas BDE47 is congener putting wild pandas at risk. 


\section{Discussion}

The first objective of this study was to test this hypothesis that giant pandas were exposed to PBDEs. Our previous research had found that $\mathrm{Br}$ in fecal samples of captive pandas were 3.3 times higher than in wild pandas (Chen et al., 2017), and data reported here supported the resulting hypothesis that captive pandas were exposed to PBDEs (Figs. 2A, 3A). In captive pandas, BDE47, BDE66, BDE71, BDE99, BDE154 were the major PBDE congeners in fecal samples, which matched the profile of PBDEs in leaves of the bamboo Bashania fargesii (Fig.

4B). This result suggests that the bamboo that is the primary food supply for pandas is the main source of PBDE exposure. Plants can accumulate high concentrations of toxicants in tissues that subsequently can accumulate and in the animals (Burreau et al. 2006; Voorspoels et al. 2007; McKinney et al. 2011; Krieger et al. 2016). Once in their body, PBDEs can lead to deficiencies in neural responses, thyroid hormone disorders, and carcinogenicity (McDonald 2002; Staskal et al. 2005; Lee et al. 2014).

Many studies have shown that PBDEs bioaccumulate in aquatic (Law et al., 2003) and terrestrial (Huwe et al., 2002; Jaspers et al., 2005; Pirard et al., 2007; Voorspels et al., 2006, 2007; Da Chen et al., 2012, 2013; Crosse et al., 2012; Andersen et al., 2015) species. However, we are aware of fes studies that sampled PBDEs in fecal samples (Zheng et al., 2015), which are an appropriately non-invasive method to sample PBDEs in a rare species like the giant panda.

The second objective of our research was to compare exposure of wild and captive pandas to PBDEs. Not surprisingly, given the anthropogenic origin of PBDEs, the $213 \mathrm{PBDE}$ was significantly higher in samples taken from captive pandas. Plants often reflect the content of 
264

265

266

267

268

269

270

271

272

273

274

275

276

277

278

279

280

281

282

283

284 organic pollutants in the environment (Collins and Finnegan, 2010) because the soil-air-plant pathway (pollutants volatilized from soils into the atmosphere are deposited onto plants) describes uptake of organic pollutants from contaminated soils (e.g., Paterson et al., 1991; Trapp and Matthies., 1997; Harrad et al., 2006; Collins and Finnegan., 2010; Ding et al., 2014). We found that the 513 PBDE of in Fargesia qinlingensis and Bashania fargesii growing around the captive breeding center was significantly higher than that growing in the nature reserve (Fig. 2B and 2C). The panda captive breeding center at SWARC is located close to the large city of Xi'an and also to several potential sources of PBDE contamination: waste incinerators, electronic-waste processing facilities, and industrial discharges (He et al., 2014; Kosior et al., 2015; Wang et al., 2015).

The final objective of our research was to identify possible sources of exposure for PBDE pollution by pandas. This study is the first to measure PBDE concentrations in bamboo, so we can compare our results only with those from unrelated plant species. The $\Sigma$ 13PBDEs of Fargesia qinlingensis and Bashania fargesii growing at FNNR and SWARC in our study were higher than that of the moss Pleurozium schreberi in uncontaminated (755.6 pg/g dry mass) or urban ( 3062.9 pg/g dry mass) areas. Pandas eat little besides bamboo. They can consume on average $30 \mathrm{~kg} /$ day (Tuanmu et al., 2013) and bamboo accounts for > 99\% of their diet (Hu, 1991, 2000), yet only $25 \%$ of the nutrients in bamboo can be assimilated (Zhou et al., 2008). This diet, together with the similarities in congener profiles of panda fecal samples (Fig. 3A) and the clustering in the PCA, (Fig. 4B) suggest that bamboo is the primary source of PDBE exposure for pandas. 

unlikely source of PBDEs for pandas. Likewise, the feedstuff appears an unlikely route of exposure. In captivity, pandas are fed a steamed bread supplement (“feedstuff”) that includes additional ingredients, including milk powder, apple, carrot, steamed bran, rice flour, maize flour, bean flour, fishmeal, bone meal, and mineral additives that provide supplemental nutrients essential for successful breeding programs (Chen and Ma, 2016). The $\Sigma 13$ PBDE in feedstuff

291 (28.8 pg·g ${ }^{-1}$; Fig. 2E) exceeded PBDEs concentrations in some farmland grains $\left(13.7 \mathrm{pg} \cdot \mathrm{g}^{-1}: \mathrm{Luo}\right.$ 292 et al., 2009) but not others (30-440 pg.g-1: Zheng et al., 2015). This might be because the feedstuff used in our research was purchased from local markets instead of having been made on site from locally-grown ingredients.

To our knowledge, this is the first investigation of exposure of pandas to PBDEs, and one of only a very few studies of PBDE exposure and bioaccumulation in a terrestrial species (Hoshi et al., 1998; Christensen et al., 2005). There are few comparables, but the HQ model for exposure risk suggests that BDE99, BDE47, and BDE153, each of which has an $H Q>1$, could threaten the health of captive giant pandas. Pandas in captive breeding centers generally are thought to be better protected from human activities than are wild pandas in nature conservation zones. However, our previous research has shown that captive pandas are exposed to a variety of environmental pollutants (Chen et al. 2016). The data presented here provide further evidence that the habitat and captive breeding centers of giant pandas are polluted by PBDEs, and that exposure to PBDEs is significantly greater in captive conditions. 
PBDEs in pandas most likely come from the bamboo they eat. Every giant panda consumes

$30 \mathrm{~kg}$ of shoots and leaves of bamboo, on average, every day (Tuanmu et al. 2013). Therefore,

even relatively low concentration of PBDEs in bamboo can still lead to a high dietary exposure

that threatens the health of the giant pandas. For mammals, PBDEs can be transferred to nursing

offspring via mother’s milk (Travis and Hattermer-Frey, 1991; Darnerud, 2003; Beineke et al.,

2005; Beineke et al., 2007). PBDEs also have immunotoxicity and can be immunosuppressants

312 (Arkoosh et al., 2010; Frouin et al., 2010; Lv et al., 2015) that make pandas more vulnerable to

bacterial and viral infections.

\section{Conclusions and Recommendations} centers, and may represent a significant health risk for pandas in captivity. We recommend that managers of these centers and captive breeding programs, including the Chinese State Forestry Administration (SFA), seek strategies to minimize PDBE exposure by pandas lest decades of successful ex situ conservation efforts become compromised by the increasing pollution associated with Chinese economic development. A short-term solution to addressing this issue is to reduce the supply of contaminated bamboo and to grow uncontaminated bamboo strictly for

322 captive pandas. In the long term, however, sustaining a successful captive breeding program for

323 pandas will require reduction of air, water, and soil pollution that will lead to improvements in the environmental quality of the giant panda's natural habitat. 


\section{Acknowledgements}

327 This research was supported by a project from SKLLQQG (State Key Laboratory of Loess and

Quaternary Geology) and IEECAS (Institute of Earth Environment, Chinese Academy of

329 Sciences (ZZBS1303)). AME's participation in this project was supported by the Chinese

Academy of Sciences (CAS) Presidential International Fellowship Initiative for Visiting

Scientists, Grant no. 2016VB074.

\section{References}

Arkoosh, M.R., Boylen, D., Dietrich, J., Anulacion, B.F., Ylitalo, G., Bravo, C.F., Johnson, L.L., Loge, F.J., Collier, T.K., 2010. Disease susceptibility of salmon exposed to polybrominated diphenyl ethers (PBDEs). Aquat. Toxicol. 98, 51-59.

Andersen, M.S., Fuglei, E., König, M., Lipasti, I., Pedersen, Å., Polder, A., Yoccoz, N.G., Routti, H, Levels and temporal trends of persistent organic pollutants (POPs) in arctic foxes (Vulpes lagopus) from Svalbard in relation to dietary habits and food availability. Sci. Total Environ. 472, 112-122.

Beineke, A., Siebert, U., McLachlan, M., Bruhn, R., Thron, K., Failing, K., Müller, G., Baumgärtner, W., 2005. Investigations of the potential influence of environmental contaminants on the thymus and spleen of harbor porpoises (Phocoena phocoena). Environ. Sci. Technol. 39, 3933-3938.

Beineke, A., Siebert, U., Stott, J., Müller, G., Baumgärtner, W., 2007. Phenotypical 
free-ranging harbor porpoises (Phocoena phocoena). Vet. Immunol. Immunop. 117, 254265.

Branchi, I., Capone, F., Alleva, E., Costa, L.G., 2003. Polybrominated diphenyl ethers neurobehavioral effects following developmental exposure. Neurotoxicol. 24, 449-462.

Burreau, S., Zebuhr, Y., Broman, D., Ishaq, R., 2006. Biomagnification of PBDEs and PCBs in organic pollutants in British Columbia grizzly bears: consequence of divergent diets. food webs from the Baltic Sea and the northern Atlantic Ocean. Sci. Total Environ. 366. 659-672.

Chen, D., Letcher, R.J., Martin, P., 2012. Flame retardants in eggs of American kestrels and European starlings from southern Lake Ontario region (North America). J. Environ. Monit. 14. 2870-2876.

Chen, D., Martin, P., Burgess, N.M., Champoux, L., Elliott, J.E., Forsyth, D.J., Idrissi, A., and Letcher, R.J., 2013. European starlings (Sturnus vulgaris) suggest that landfills are an important source of bioaccumulative flame retardants to Canadian terrestrial ecosystems. Environ. Sci. Technol. 47. 12238-12247.

Chen, Y.P., Maltby, L., Liu, Q., Song, Y., Zheng, Y.J., Ellison, A.M., Ma, Q.Y., Wu, X.M., 2016. Captive pandas are at risk from toxic chemicals. Front. Ecol. Environ. 14. 363-367. Chen, Y.P., Ma, Q.Y., 2017. Supplement nutrition has potential risk for captive pandas. J. Earth Environ. (in press).

Christensen, J.R., MacDuffee, M., Macdonald, R.W., Whiticar, M., Ross, P. 2005. Persistent Environ. Sci. Technol. 39, 6952-6960. 
368 Collins, C.D., Finnegan, E., 2010. Modeling the plant uptake of organic chemicals, including the soil-air-plant pathway. Environ. Sci. Technol. 44, 998-1003.

370

371

372

373

374

375

376

377

378

379

380

381

382

383

384

385

386

387

Crosse, J.D., Shore, R.F., Wadsworth, R.A., Jones, K.C., Pereira, G., 2012. Long-term trends in pbdes in sparrowhawk (Accipiter nisus) eggs indicate sustained contamination of UK terrestrial ecosystems. Environ. Sci. Technol. 46, 13504-13511.

Darnerud, P.O., 2003. Toxic effects of brominated flame retardants in man and in wildlife. Environ. Int. 29, 841-853.

Darnerud, P.O., Thuvander, A., 1998. Studies on immunological effects of polybrominated diphenyl ethers (PBDE) and polychlorinated biphenyl (PCB) exposure in rat and mice. Organohalogen Compd. 35, 415-418.

Darnerud, P.O., Eriksen, G.S., Johannesson, T., Larsen, P.B., Viluksela, M., 2001. Polybrominated diphenyl ethers: occurrence, dietary exposure, and toxicology. Environ. Health Persp. 109, 49-68.

De Wit, C.A., 2002. An overview of brominated flame retardants in the environment. Chemosphere 46, 583-624.

Ding, C., Chang, W.J., Zeng, H., Ni, H.G., 2014. Field and modeling study of PBDEs uptake by three tree species. Sci. Total Environ. 472, 923-92.

Eriksson, P., Jakobsson, E., Fredriksson, A., 2001. Articles brominated flame retardants: a novel class of developmental neurotoxicants in our environment? Environ. Health Persp. 109, 903-908. 
Fowles, J.R., Fairbrother, A., Baechersteppan, L., Kerkvliet, N.I., 1994. Immunological and endocrine effects of the flame-retardant pentabromodiphenyl ether de-71 in c57blr6j mice. Toxicology 86, 49-61.

Frouin, H., Lebeuf, M., Hammill, M., Masson, S., Fournier, M., 2010. Effects of individual polybrominated diphenyl ethers (PBDE) congeners on harbour seal immune cells in vitro. Mar. Pollut. Bull. 60, 291-298.

Hang, X.S., Wang, H.Y., Zhou, J.M., Ma, C.L., Du, C.W., Chen, X.Q., 2009. Risk assessment of potentially toxic element pollution in soils and rice (Oryza sativa) in a typical area of the Yangtze River Delta. Environ. Pollut. 157, 2542-2549.

Harrad, S., Ren, J., Hazrati, S., Robson, M., 2006. Chiral signatures of PCB\# s 95 and 149 in indoor air, grass, duplicate diets and human faeces. Chemosphere 63, 1368-1376.

He, W., Qin, N., He, Q.S., Kong, X.Z., Liu, W.X., Wang, Q.M., Yang, C., Jiang, Y.J., Yang, B., Bai, Z.L., Wu, W.J., Xu, F.L. 2014. Atmospheric PBDEs at rural and urban sites in central China from 2010 to 2013: residual levels, potential sources and human exposure. Environ. Pollut. 192, 232-243.

Hooper, K., McDonald, T.A., 2000. The PBDEs: An emerging environmental challenge and another reason for breast-milk monitoring programs. Environ. Health Persp. 108, 387.

Hoshi, H., Minamoto, N., Iwata, H., Shiraki, K., Tatsukawa, R., Tanabe, S., Fujita, S., Hirai, K., Kinjo, T. 1998. Organochlorine pesticides and polychlorinated biphenyl congeners in wild terrestrial mammals and birds from Chubu Region, Japan: Interspecies Comparison of the Residue Levels and Compositions. Chemosphere 36, 211-3221. 
Hu, G.C., Luo, X.J., Dai, J.Y., Zhang, X.L., Wu, H., Zhang, C.L., Guo, W., Xu, M.Q., Mai, B.X., Weit, F.W. 2008. Brominated flame retardants, polychlorinated biphenyls, and organochlorine pesticides in captive giant panda (Ailuropoda melanoleuca) and red panda (Ailurus fulgens) from China. Environ. Sci. Technol. 42: 4704-4709.

Hu, J.C., 1991. Habitating environment of giant pandas and food base. A special topic of zoology. Beijing University Press, Beijing, in Chinese.

Hu, J.C., 2000. Review on the classification and population ecology of the giant panda. Zool. Res. 21, 28-34.

Huwe, J.K., Lorentzsen, M., Thuresson, K., Bergman, A., 2002. Analysis of mono- to deca-brominated diphenyl ethers in chickens at the parts per billion level. Chemosphere 46, 635-640.

Jaspers, V., Covaci, A., Maervoet, J., Dauwe, T., Voorspoels, S., Schepens, P., Eens, M., 2005. Brominated flame retardants and organochlorine pollutants in eggs of little owls (Athene noctua) from Belgium. Environ. Pollut. 136, 81-88.

Kim, T.H., Bang, D.Y., Lim, H.J., Won, A.J., Ahn, M.Y., Patra, N., Chung, K.K., Kwack, S.J., Park, K.L., Han, S.Y., Choi, W.S., Han, J.Y., Lee, B.M., Oh, J.E., Yoon, J.H., Lee, J., Kim, H.S. 2012. Comparisons of polybrominated diphenyl ethers levels in paired South Korean cord blood, maternal blood, and breast milk samples. Chemosphere 87, 97-104. Kosior, G., Klánová, J., Vanková, L., Kukucka, P., Chropenová, M., Brudzinska-Kosior, A., Samecka-Cymerman, A., Kolon, K., Kempers, A.J., 2015. Pleurozium schreberi as an 
ecological indicator of polybrominated diphenyl ethers (PBDEs) in a heavily industrialized urban area. Ecol. Indic. 48, 492-497.

Krieger, L.K., Szeitz, A., Bandiera, S.M. 2016. Evaluation of hepatic biotransformation of polybrominated diphenyl ethers in the polar bear (Ursus maritimus). Chemosphere 146, $555-564$.

Lee, H.J., An, S., Kim, G.B. 2014. Background level and composition of polybrominated diphenyl ethers (PBDEs) in creek and subtidal sediments in a rural area of Korea. Sci Total Environ 470-47, 1479-1484

Legler, J., Brouwer, A., 2003. Are brominated flame retardants endocrine disruptors? Environ. Int. 29, 879-885.

Li, Y.M., Jiang, G.B., Wang, Y.W., Wang, P., Zhang, Q.H., 2008. Concentrations, profiles and gas-particle partitioning of PCDD/Fs, PCBs and PBDEs in the ambient air of an E-waste dismantling area, Southeast China. Chin. Sci. Bull. 53, 521-528.

Law, R.J., Alaee, M., Allchin, C.R., Boon, J.P., Lebeuf, M., Lepom, P., Stern, G.A., 2003. Levels and trends of polybrominated diphenylethers and other brominated flame retardants in wildlife. Environ. Int. 29, 757-770.

Luo, X.J., Liu, J., Luo, Y., Zhang, X.L.,Wu, J.P., Lin, Z., Chen, S.J., Mai, B.X., Yang, Z.Y. 2009. Polybrominated diphenyl ethers (PBDEs) in free-range domestic fowl from an e-waste recycling site in South China: levels, profile and human dietary exposure. Environ. Int. 35, 253-258. 
Lv, Q.Y., Wan, B., Guo, L.H., Zhao, L., Yang, Y., 2015. In vitro immune toxicity of polybrominated diphenyl ethers on murine peritoneal macrophages: apoptosis and immune cell dysfunction. Chemosphere 120, 621-630.

Mara, H., 2015. Captive pandas succumb to killer virus. Science 347, 700-701.

McDonald, T.A. 2002. A perspective on the potential health risks of PBDEs. Chemosphere 46, $745-755$.

McKinney, M.A., Dietz, R., Sonne, C., Guise, S.D., Skirnisson, K., Karlsson, K., Steingrimsson, E., Letcher, R.J. 2011. Comparative hepatic microsomal biotransformation of selected PBDEs, including decabromodiphenyl ether, and decabromodiphenyl ethane flame retardants in Arctic marine-feeding mammals. Environ. Toxicol. Chem. 30, 1506-1514.

Paterson, S., Mackay, D., Bacci, E., Calamari, D., 1991. Correlation of the equilibrium and kinetics of leaf-air exchange of hydrophobic organic chemicals. Environ. Sci. Technol. 25, 866-871.

Pirard, C., DePauw, E., 2007. Absorption, disposition and excretion of poly-brominated diphenylethers (PBDEs) in chicken. Chemosphere 66, 320-325.

SFA (State Forestry Administration)., 2015. The 4th national survey report on giant panda in China. Science Press, Beijing (in Chinese).

Staskal, D.F., Diliberto, J.J., DeVito, M.J., Birnbaum, L.S. 2005. Toxicokinetics of BDE 47 in female mice: effect of dose, route of exposure, and time. Toxicol. Sci. 83, 215-223.

Trapp, S., Matthies, M., 1997. Modeling volatilization of PCDD/F from soil and uptake into vegetation. Environ. Sci. Technol. 31, 71-74. 
Travis, C.C., Hattermer-Frey, H.A., 1991. Human exposure to dioxin. Sci. Total Environ. 104, 97-127.

Tuanmu, M.N., Vina, A., Winkler, J.A., Li, Y., Xu, W.H., Ouyang, Z.Y., Liu, J.G., 2013. Climate-change impacts on understorey bamboo species and giant pandas in China’s Qinling Mountains. Nat. Clim. Change 3, 249-253.

US EPA. 1997. Exposure factors handbook; EPA/600/P-95/002Fa, b, c; Environmental Protection Agency. Office of Research and Development, Washington, DC.

Voorspoels, S., Covaci, A., Jaspers, V.L.B., Neels, H., Schepens, P. 2007. Biomagnification of PBDEs in three small terrestrial food chains. Environ. Sci. Technol. 41, 411-416.

Wang, J.X., Liu, L.L., Wang, J.F., Pan, B.S., Fu, X.F., Zhang, G., Zhang, L., Lin, K.F., 2015. Distribution of metals and brominated flame retardants (BFRs) in sediments, soils and plants from an informal e-waste dismantling site, South China. Environ. Sci. Pollut. Res. 22, 1020-1033.

WHO, World Health Organization., 1994. Brominated Diphenyl Ethers. IPCS, Environmental Health Criteria. Geneva, PP.162.

Zheng, X.B., Luo, X.J., Zheng, J., Zeng, Y.H., Mai, B.X., 2015. Contaminant sources, gastrointestinal absorption, and tissue distribution of organohalogenated pollutants in chicken from an e-waste site. Sci. Total Environ. 505, 1003-1010.

Zhou, S.Q., Huang, J.Y., Liu, B., Zhang, Y.H., Tan, Y.C., Zhou, X.P., Huang, Y., Li, D.S., Zhang, G.Q., Wei, R.P., Tang, C.X., Wa, P.Y., Zhang, H.M., 2008. A preliminary study 
